\title{
New Logistics System with E-Commerce and Cloud Computing Technology
}

\author{
Yang Chunlin \\ School of Information Engineer, Lanzhou University of Finance and Economics \\ Lanzhou city, China \\ yangcl@lzcc.edu.cn
}

\begin{abstract}
With the CPI keeps rising in some countries, some research institutions pointed out that one of the important reasons is the logistics. This paper come up with a solution Cloud Computing and E-Commerce technology to solve this problem. We researched into the costs of Chinese logistics. The purpose of this study is to use the Cloud Computing and E-Commerce technologies. The solution can substantially lower the costs of the logistics industry up to $30 \%$. We have finished some nuclear technologies. The results suggest a widespread method to develop the logistics industry.
\end{abstract}

Keywords- Logistics, Cloud Computing, E-Commerce, Management, Costs

\section{INTRODUCTION}

With the CPI in China keeps rising, some research institutions pointed out that one of the important reasons is the logistics. In the report released by the government, we can see in the price of some primary products, the logistics costs as much as $75 \%$. Now it becomes a headache to the government about the logistics costs.

In fact many industries nowadays are confronted with such problems, our research group has always been studying this topic, and we come up with a solution that is using information technology to solve the high costs problem. And constructing big logistics system in China with Cloud Computing and E-Commerce technology is an excellent choice.

Now in China there are about ten thousand logistics corporations, cases are like this, most of them is rely on the truck transports. When one driver arrives at the destination and finishes sending the goods to his customers, he will come back with an empty truck. So we can reduce $25 \%$ costs by raising the service efficiency of trucks. In order to do it, the government has to build a shared information platform, the software that can scout the situation and states of all the trucks instantly, and share the orders of all the customers. Thus, we can avoid coming back with an empty truck. Theoretically, according to our calculation, we think it can at least lower $25 \%$ costs in logistics system. There are some features in this platform: lower charge, lower investment, lower maintenance costs and higher efficiency. After the platform is running in gear, the government can authorize it to a third party company to manage.

We have done a lot of investigations and surveys, and we find that in some Developed Countries, they have already been using this method to reduce the logistics costs, for example, France. But the costs of the platform are too expensive to use in China, because most logistics companies in China are small business, so if the price is too high, the companies can't apply for the cost. Therefore in the China, the key is to reducing the costs. That is, a cheap platform is the precondition.

If some companies want to build a Web-based application, the traditional way is to choose Dedicated Hosting or build a self computer cluster. But both methods are too expensive to Chinese Logistics Companies. But now the Cloud Computing technology is a very appropriate for this application. It's a low-cost and it owns abundant computing resource, and the most important is that the TCO (Total Cost Ownership) is close to zero.

Cloud Computing platform is a general concept, it is made up of several parts, the kernel is called IaaS(now China Telecom and China Mobile company have applied these services ), Here are some key parts:[3]

- IaaS: Infrastructure-as-a- Service.

- PaaS: Platform-as-a- Service.

- SaaS: Software-as-a- Service.

But now some solutions provided by IaaS is not adapted to build a big logistics system which is based on Web, so the IaaS company must grasp the needs in this field, and develop an OS software, Storage-Management system and DBMS(Database manage system). And that's the key to solving the problem. We have designed a solution to solve it. The following is our general solution.

\section{ADVANTAGES AND DISADVANTAGES OF CLOUD COMPUTING}

\section{A. Advantages}

The concept makes no sense unless it is under a specific application. This is because the low costs of Cloud Computing are relying on the special environment. So our purpose is to constructing a big logistics system in China with Cloud Computing and E-Commerce technology.

Cheapness is a label about the Cloud Computing. It is the delivery of computing as a service rather than a product, and the customers can share resources, software, and information which are offered by computers and other devices as a utility (like the electricity grid) over a network (typically the Internet). [1]

When the business software and data are stored on servers at a remote location, Cloud computing providers can deliver applications through the Internet, which are accessed from a web browser. In some cases, legacy applications (line of business applications which have been prevalent in thin client Windows computing until now) are delivered by 
a screen-sharing technology, while the computing resources are consolidated at a remote data center location; in other cases, entire business applications have been coded using web-based technologies such as AJAX or .Net. [2]

To put it simple, some companies don't have enough financing, and can't maintain or afford complex ClusterServers and complex storage system, but now they can use IaaS' computing resources. These resources are called Cloud Computing. To these companies, it can not only save money in IT investment, but also avoid the problems of maintaining and updating.

Now the Cloud computing technology has matured. Although there are some problems to be solved, but our antecessors have gathered good experience. There are some successful applications, such as Google, Open Stack, etc.

\section{B. Disadvantages}

\section{1) Costliness in Infrastructure.}

Cloud computing is a concept, and there are some experience but no uniform standards. Nor in the future, we think. The Cloud computing is low in cost, but to IaaS, the first investment is dear, because IaaS must develop server cluster management software, storage system software, even DBMS. For example, Google developed a database named Big Table. It is a distributed storage system for managing structured data that is designed to scale to a very large size, and abandoned the transactions and other complex features, peta bytes of data across thousands of commodity servers. Many projects at Google store data in Big Table, including web indexing, Google Earth, and Google Finance.[3]

But it is beyond imagination if you decide to develop these softwares by yourself. All IaaS of Cloud computing are in virtue of the Open Source, and to sum it up is "to outsource ". That is, making use of the Linux and MySQL, and the design only requires moderate modification. But as an IaaS, one must be capable of putting forward a perfect blueprint in detail. Now the programs of some large outsource companies in China are related to Cloud computing. But it's a pity that few Chinese companies dive into developing their own Cloud computing foundation platform.

\section{2) Bandwidth and Web.}

Applications based on Cloud computing must via Web to function unless one is an IaaS itself. So as to the customers, there are two important problems to be solved: one is enough bandwidth, the other is Web applications. If you must use data warehouse or analogous demands, the Cloud computing may not be suitable.

In general, Cloud computing platform give us a brandnew choice, and tenantable computing resource, and it will sure have a great influence on IT industry.

\section{DESIGN OF ARCHITECTURAL PATTERN}

\section{A. The current situation and problems}

Now there are over ten thousand of logistics companies in China, which result in considerable high-cost in the industry, thus making the price of commodities raise by $25 \%$. We have investigated twelve logistics companies in Gansu province, China. The data shows that it's about $30 \%$ of transports come back without goods, so the costs increased about $25 \%$ for each transport. The following is a table about it.

TABLE I. TRANSPORT ABOUT TWELVE LOGISTICS COMPANIES

\begin{tabular}{|c|c|c|c|c|}
\hline $\begin{array}{c}\text { Wagon } \\
\text { number }\end{array}$ & $\begin{array}{c}\text { Departure } \\
\text { point- } \\
\text { destination }\end{array}$ & $\begin{array}{c}\text { Expense } \\
\text { of full } \\
\text { load(unit: } \\
\text { Yuan) }\end{array}$ & $\begin{array}{c}\text { Expense } \\
\text { of empty } \\
\text { load(unit: } \\
\text { Yuan) }\end{array}$ & $\begin{array}{c}\text { The times } \\
\text { of empty } \\
\text { load from } \\
\text { January to } \\
\text { July in2011 }\end{array}$ \\
\hline$* * * * *$ & $\begin{array}{c}\text { Lanzhou- } \\
\text { Wuhan }\end{array}$ & 9200 & 2700 & 34 \\
\hline$* * * * *$ & $\begin{array}{c}\text { Lanzhou- } \\
\text { Xi'an }\end{array}$ & 4500 & 940 & 22 \\
\hline \multicolumn{4}{|c}{$\ldots \ldots \ldots \ldots$} \\
\hline
\end{tabular}

In our inquiry, we find that the drivers are unwilling to come back with empty trucks, but they are trying to do something. The logistics companies and the drivers often contact with familiar local logistics companies and transport goods if they would like. But this mode is inefficient.

According to the data published by the National Bureau of Statistics of China, the total amount of logistics is up to 710 billion RMB in 2010, and the annual growth rate is $15 \%$, and the total amount of the logistics costs is about $17.8 \%$ of the GDP[4].

If we suppose the empty transport proportion is $20 \%$, we can draw a conclusion that the whole society has to pay extra money of 140 billion RMB. If the empty transport proportions reduce by $1 \%$, and thus we can save 7 billion RMB every year.

\section{B. Solutions}

The government is expected to build a logistics Web Platform. All the logistics companies take part in it as a Web service leaseholder. The platform is a big information center, and it contains all the logistics companies' truck positions and goods conditions, so we can share the logistics information and avoid the inefficiency transport. [5]

On the other hand, shippers also can use the platform and publish his freight information, and find a reasonable transportation pattern. [6]

1) Requirement Analysis.

Now many companies are designing foundation structure of Cloud computing as a IaaS, and some have already been put into operation. But based on the logistics Web application, Cloud computing have some special features.

Here they are:

- Lower data size, data collection happened only when each goods or a truck arrived at a special position, and data amount is about some kilobytes.

- Real-time request is low, and a delay within an hour is allowed. 
- $\quad$ It can support GIS and GPS by many ways, which is very important to the logistics application.

- A moderate cost

Under the analysis above, we can draw some conclusions as following:

- Lower storage size.

- Higher security demands.

- Lower needs for computation resources.

- $\quad$ Lower real-time demands.

- $\quad$ Support GIS and GPS.

- A moderate cost.

- The system can support as many as 20,000 users, and have backup data.

- It has no real-time demand to the data from GPS.

2) Hardware Features.

We designed a Cloud computing platform (short specification):

Servers: PC Xeon Server;

Storages: Two storages system backup each other;

Interface: Link in CHINANET.

Management Software: We have reworked the Linux kernel to strengthen the storage management.

To DBMS, we chose the MySQL , and we designed it as Google's Big Table.

If the scheme above is adopted, we can get a lower cost Cloud computing platform.

To small logistics companies, the project above is the most suitable, but if you are in a large-scale logistics company, plenty bandwidth is very important, and you have to redeploy your ERP system. [7]

Now some IaaS have been supplying the service, and its price is cheaper than traditional Domain Tenancy. But to these IaaS, it's also important to modify their hardware structure.

\section{3) Application softwares.}

There are two important problems to be solved: sharing of logistics information and management features. To the sharing of logistics information, there is a moderate cost in developing software, because the technology is mature, we have developed a foundation platform, and have spent about ten hundreds man-hours. In the platform, we have developed the interface on GIS, GPS and ERP (SAP)

A nationally logistics platform should focus on the efficiency but not income. Some larger companies need logistics information from all parts of the country, and it's important to provide the ERP interface for these companies. [8]

The nationally logistics platform should serve the B2C web companies, for example the TaoBao Web Site etc.

We believe our Cloud Computing and E-Commerce Logistics System will make a big difference on the Chinese Logistics.

\section{REFERENCES}

[1] Wang, L., Tao, L., Kunze, M. Castellanos, A., Kramer, C. D. , \& Karl, W. (2008). "Scientific Cloud Computing: Early Definiyion and Experience". HPCC:08, IEEE Computer Socity. Washington, DC:IEEE Computer Socity, p.825.

[2] Luis M. Vaquero, Lius Rodero, Juan Caceres, Maik Linder. "A Break in the clouds:towards a cloud difinition". ACM SIGCOMM Computer Communication Review, 2008,p.1-10.

[3] Martin Christopher. "Logistics and Supply Chain Management:Strategies for Reducing Cost and Improving Service", 2002 , 2002,p.271.

[4] National Bureau of Statistics of China. 16-9 Freight Ton-Kilometers, http://www.stats.gov.cn/tjsj/ndsj/2010/html/P1609e.htm.

[5] U.S. Census Byreau, "United States Logistics and Express OutlookAn analysis of the logistics and express markets in the United States,” http://www.census.gov/2010Census, unpublished.

[6] Borko Furht, Armando Escalante, "Handbook of Cloud Computing” Springer New York Dordrecht Heidelberg London 2010, p.576.

[7] D.F.Ross, "Distribution Planning and Control", Kluwer Academic Publishers, Norwell, Mass, USA 1998.

[8] Cook, R.L, "Case-based reasoning system inpurchasing:applications and development", International Jouranl of Purchasing and Materials Management. 1997, 33(1), p.32-39. 